\title{
Research Paper: Addressing Bowel Dysfunction in Men Aging With Spinal Cord Injury
}

\author{
Mohammadreza Abed $^{1}$ (D), Zohreh Raeisi ${ }^{*}$ (D), Hasan Rezaei-Jamalouei ${ }^{1}$ (D), Mojtaba Ansari Shahidi ${ }^{1}$ (i) \\ 1. Department of Psychology, Najafabad Branch, Islamic Azad University, Najafabad, Iran.
}

Citat on: Abed M, Raeisi Z, Rezaei-Jamalouei H, Ansari Shahidi M. Research Paper: Addressing Bowel Dysfunction in Men Aging With Spinal Cord Injury. Iranian Rehabilitation Journal. 2021; 19(3):297-306. http://dx.doi.org/10.32598/irj.19.3.1426.1

doi ${ }^{h} h t$ tp://dx.doi.org/10.32598/irj.19.3.1426.1

Article info:

Received: 30 Apr 2021

Accepted: 27 Jul 2021

Available Online: 01 Sep 2021

\section{Keywords:}

Bowel dysfunction, Aging, Spinal Cord Injury (SCI)

\section{A B STRACT}

Objectives: Spinal Cord Injury (SCI) increases the frequency and severity of bowel problems, especially for those who age with this injury. The present study aimed to investigate the effectiveness of a bowel management training program in patients aged with SCI.

Methods: A multiple-baseline single-case design of concurrent type was employed. Three male married patients with SCI whose ages ranged between 48 and 53, with a mean duration of 32 years after the injury, were recruited for this study from a rehabilitation center in Isfahan City, Iran, in 2020. An individualized 8-week bowel management training program was conducted. The patients' bowel dysfunction was evaluated by Neurogenic Bowel Dysfunction (NBD) score.

Results: The results were provided by the six features of single-case designs, namely immediacy of the effect, overlap, variability consistency of data patterns across similar phases, trend, and level, revealed the efficacy of the program in decreasing bowel dysfunction problems in men aging with SCI.

Discussion: Health care providers should know about the changes that might happen as an individual gets old with SCI to take preventive measures and reduce the harmful effects of aging, especially bowel dysfunction. 


\section{Highlights}

- The area of aging and SCI is under research.

- Bowel dysfunction is among the most prevalent problems in individuals with SCI.

- This study is among the few ones focused on bowel dysfunction management training in individuals aged with SCI.

\section{Plain Language Summary}

Spinal Cord Injury (SCI) is caused by injury to the spinal cord that might end in temporary or permanent changes in this part. Its symptoms are loss of sensation, muscle function, or autonomic function in the body parts below the level of the injury. Bowel dysfunction is among the most prevalent consequences of SCI and might increase depression and anxiety levels in patients. The present study aimed to investigate the effect of a bowel management training program on patients aged with SCI. For this purpose, three male married patients with SCI whose ages ranged between 48 and 53, with a mean duration of 32 years after injury, were recruited for this study. An individualized 8-week bowel management training program was conducted. The results revealed the efficacy of the program in decreasing bowel dysfunction problems in men aging with SCI.

\section{Introduction}

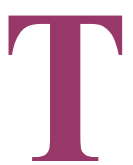

he absence of normal bowel function is one of the most annoying problems for those with Spinal Cord Injury (SCI) $[1,2]$. More than $98 \%$ of people with SCI experience at least one bowel problem (i.e., constipation, incontinence, and so on) [3] due to their injury. The bowel dysfunction might range from moderate to severe, placing significant limitations on their quality of life and social activities $[4,5]$. Furthermore, bowel care is very time-consuming and might increase depression and anxiety levels in patients with SCI [6].

Exploring this issue from the aging perspective, researchers have shown that aging negatively influences the physical and social functioning of individuals with SCI and results in problems like bowel complications $[7,8]$. These studies documented several gastrointestinal problems associated with the aging process and highlighted further need for the elders' daily activities [9]. Since SCI considerably changes the colorectal function, it necessitates a "bowel program" that includes an amalgamation of diet, pharmaceuticals, and varied intestinal reflexes; furthermore, the distorted colorectal function might cause problems in the patients aged with SCI [10].

A longitudinal study with individuals more than 20 years after SCI reported that $27 \%$ of them mentioned fecal incontinence, $35 \%$ experienced gastrointestinal pain, and $42 \%$ had difficulties with constipation [11]. An even greater prevalence of fecal incontinence and constipation in about $86 \%$ of those with SCI was stated in another study [12]. Therefore, ongoing education by healthcare providers might influence the bowel outcomes of aging and their potential effect on individuals with SCI [12].

The years after SCI might be associated with the increase in the rate of the aging process since the physiologic reserves reduce and demands on functioning body systems such as the gastrointestinal system increases. Therefore, patients who age with SCI need special attention and care. According to the points mentioned above, the present study, which, to the best of researchers' knowledge, is among the few studies conducted on aging and SCI, aimed to address the bowel dysfunction problem in men aging with SCI using a bowel management training program.

\section{Materials and Methods}

\section{Study design}

A concurrent multiple-baseline design (A-B+C followup) was used in the present study. Such designs eliminate the need to return to baseline and therefore are particularly suited for evaluation of intervention with long-lasting effects, such as rehabilitation effects [7, 13] This study was conducted in Shahid Rajaei Specialized Hospital, Isfahan City, Iran, in 2020.

\section{Study participants}

Krasny-Pacini and Evans [13] stated that "the term single-case experimental designs (SCEDs) refers to a set 
of experimental methods that can be used to test the efficacy of an intervention using a small number of patients (typically one to three), and involve repeated measurements" [1]. Therefore, Three male married patients with SCI were recruited for this study (Table 1). It is noteworthy that before conducting the study, the patients' informed consent to participate was obtained.

\section{Study measures}

Neurogenic Bowel Dysfunction (NBD) was designed by Krogh et al. [14] to measure how severe colorectal dysfunction is in patients with SCI. The NBD score comprises ten items of frequency and time taken for defecation, discomfort, perspiration or headache during defecation, regularly using constipation tablets and drugs, evacuation of the anorectum or digital stimulation, feces incontinence frequency, drugs taken for feces incontinence, and problems in perianal skin caused by the quality of life impairment due to bowel symptoms. The total NBD score is between 0 and 47, with a higher score indicating bowel symptoms that can be more severe.

\section{Procedure and data analysis}

The three male patients with SCI participated in an individualized 8-week bowel management training program inspired by Badiali et al. [15] and Coggrave et al. [16]. One 45-min session was held each week. The training program was conducted by the first author of the study, a PhD holder of Health Psychology with many years of working closely with patients aged with SCI.

Three baseline measures were taken from the patients, and they were assessed every two weeks. Besides, three follow-up measurements were taken as well. The first one was taken three weeks following the end of the intervention, and the subsequent two follow-up measurements were conducted three and six weeks after the first one. Diet modification (more fiber consumption), abdominal massage (to instigate the stool movement in the colon), perianal and anorectal digitation (to instigate the relaxation of anus/rectum contraction) were included and taught in this training program. YouTube videos were also used to visualize the explanations.

Data analysis was conducted by the EXCEL program, as suggested by scholars of the single-case design studies $[17,18]$. To evaluate the effect of such studies, six features are commonly used to analyze the data patterns of within- and between phases, namely variability, the immediacy of the effect, overlap, trend, data patterns consistency across similar phases and levels.

\section{Results}

A figure was initially drawn using the data gathered from the three baselines, four during-intervention, and three follow-up measurements of each patient to analyze the data obtained from this single case study. Next, the in-situation and between-situations analyses were performed, and the changes in different measurement stages were presented in Tables 2-4.

As shown in Figure 1, no change occurred in the baseline level, yet a decrease was observed from baseline to the intervention sessions in line with the treatment goals. The same pattern was also observed in the follow-up measurements. These findings indicate the efficacy of the training program of bowel dysfunction management for the patients. The in-situation and between-situations analyses and the changes in different measurement stages are presented for each patient in the following tables.

As it is shown in the "in-situation" section of Table 2, the mean and median values decreased across the three situations, i.e., A (baseline), B (intervention), and C (follow-up). The decrease was from 31 to 9 for both median and mean. The trend's stability, which shows the slope of the best-fitting line, shows that the trend was stable at all three phases. In the "between-situations" section, the three phases were compared. As shown here, the Percentage of Non-overlapping Data (PND) of intervention and baseline phases was $100 \%$, while this value was zero for the intervention and follow-up phases. Besides, the value of $100 \%$ for the Percentage of Overlapping Data (POD) reveals data maintenance after intervention sessions. In general, the findings revealed the efficacy of the bowel management training program for the first patient.

With regard to the second patient, the median and mean values of the three situations decreased from 28 to 12 , which indicates a decrease in bowel dysfunction problems of the second patient from baseline to follow-up (from A to C). In the "between-situations" analysis, the PND of intervention and baseline phases was $100 \%$, and the POD reveals data maintenance after intervention sessions. Altogether, the training program was successful at reducing the bowel problems of the second patient.

The "in-situation" section of Table 4 illustrates that the median value decreased from 22 to 3 , and the mean decreased from 22 to 3.5 . These values indicate the efficacy of the intervention for the patient. The PND of intervention and baseline phases was $75 \%$, and the POD reveals data maintenance after intervention sessions. As a result, the training program was effective for the third patient. 
Table 1. Bowel and neurological characteristics of the study patients

\begin{tabular}{ccccccc}
\hline No. & Age (y) & Injury Level & Cause & Duration (y) & Bowel Frequency/Week & Stimuli to Evacuate \\
\hline 1 & 53 & C5-6 & Trauma & 30 & Less than 2 & Manual evacuation \\
2 & 54 & T2 & Trauma & 37 & Less than 2 & Manual evacuation \\
3 & 48 & T2-3 & Trauma & 29 & $2-3$ & $\begin{array}{c}\text { oral laxative + Manual } \\
\text { evacuation }\end{array}$ \\
\hline
\end{tabular}

\section{Discussion}

The present study aimed to address bowel dysfunction of men aged with SCI using a bowel management training program whose results revealed a decrease in bowel problems of such patients. As stated by Coggrave et al. [16], although programs for bowel management are established on routines, dietary control, using laxatives, pharmacological and digital stimulation of rectum, evac- uating manually, and helpful techniques such as massaging the abdomen, "there is little evidence to support these interventions individually or in combination" (p. 504). The present study findings supported the beneficial effect of using the above-mentioned therapeutic techniques in combination, especially for the patients aged with SCI.

Krassioukov et al. [19] stated that neurogenic bowel dysfunction might result in prolonged bowel transit time,

Table 2. In-situation and between-situations analyses for bowel dysfunction management of the first patient

\begin{tabular}{|c|c|c|c|c|c|c|}
\hline In-Situation & & & & Between-Situations & \multirow[b]{2}{*}{ B } & \multirow[b]{2}{*}{$\mathrm{C}$} \\
\hline \multirow{2}{*}{ 1. Situations' sequence } & \multirow{2}{*}{ A } & \multirow{2}{*}{ B } & \multirow{2}{*}{ C } & 1. Situation & & \\
\hline & & & & Comparison & A & $\mathrm{B}$ \\
\hline 2. Situations' length & 3 & 4 & 3 & 2. Trend variations & & \\
\hline \multirow[t]{2}{*}{ 3. Level } & & & & \multirow[t]{2}{*}{ 2.1. Direction change } & Decreasing & Zero slope \\
\hline & & & & & Zero slope & Decreasing \\
\hline 3.1. Median & 31 & 12.5 & 9 & 2.2. Target based effect & Positive & Negative \\
\hline \multirow{2}{*}{ 3.2. Mean } & \multirow{2}{*}{31} & \multirow{2}{*}{15} & \multirow{2}{*}{9} & \multirow{2}{*}{ 2.3. Stability variation } & & \\
\hline & & & & & Stable & Stable \\
\hline 3.3. Range of variations & $31-31$ & $6-29$ & $9-9$ & 3. Level change & & \\
\hline \multirow{2}{*}{$\begin{array}{l}\text { 3.4. Variation range in } \\
\text { stability envelope } \\
25 \% \text { of median }\end{array}$} & \multirow{2}{*}{$\begin{array}{l}23.25-38.75 \\
\text { Stable }\end{array}$} & \multirow{2}{*}{$\begin{array}{c}4.75-20.25 \\
\text { Variable }\end{array}$} & \multirow{2}{*}{$\begin{array}{c}1.25-16.75 \\
\text { Stable }\end{array}$} & \multirow{2}{*}{ 3.1. Relative variation } & 25 & 12 \\
\hline & & & & & 28 & 11 \\
\hline \multirow{2}{*}{ 4. Level change } & \multirow[t]{2}{*}{7.75} & \multirow[t]{2}{*}{7.75} & \multirow[t]{2}{*}{7.75} & \multirow{2}{*}{ 3.2. Absolute variation } & 26 & 12 \\
\hline & & & & & 28 & 10 \\
\hline \multirow{2}{*}{ 4.1. Relative variation } & \multirow{2}{*}{$31-31$} & \multirow{2}{*}{$22.5-7.5$} & \multirow{2}{*}{$9-9$} & \multirow{2}{*}{ 3.3. Median variation } & 15 & 12 \\
\hline & & & & & 28 & 18 \\
\hline \multirow{2}{*}{ 4.2. Absolute variation } & \multirow{2}{*}{$31-31$} & \multirow{2}{*}{$29-6$} & \multirow{2}{*}{$9-9$} & \multirow{2}{*}{ 3.4. Mean variation } & 18 & 12 \\
\hline & & & & & 28 & 18 \\
\hline 5. Trend & & & & 4. Data overlap & & \\
\hline 5.1. Direction & Zero slope & Decreasing & Zero slope & 4.1. PND & $100 \%$ & $0 \%$ \\
\hline 5.2. Stability & Stable & Stable & Stable & 4.2. POD & $0 \%$ & $100 \%$ \\
\hline 5.3. Multiple routes & No & No & No & & & \\
\hline
\end{tabular}


Table 3. In-situation and between-situations analyses for bowel dysfunction management of the second patient

\begin{tabular}{|c|c|c|c|c|c|c|}
\hline In-Situation & & & & Between-Situations & \multirow{3}{*}{ B } & \multirow{3}{*}{ C } \\
\hline \multirow{3}{*}{ 1. Situations' sequence } & \multirow{3}{*}{ A } & \multirow{3}{*}{ B } & \multirow{3}{*}{ C } & \multirow[t]{2}{*}{ 1. Situation } & & \\
\hline & & & & & & \\
\hline & & & & comparison & A & B \\
\hline 2. Situations' length & 3 & 4 & 3 & 2. Trend variations & & \\
\hline \multirow[t]{2}{*}{ 3. Level } & & & & \multirow{2}{*}{ 2.1. Direction change } & & \\
\hline & & & & & Zero slope & Decreasing \\
\hline 3.1. Median & 28 & 18 & 12 & 2.2. Target based effect & Positive & Negative \\
\hline \multirow{3}{*}{ 3.2. Mean } & \multirow{3}{*}{28} & \multirow{3}{*}{18} & \multirow{3}{*}{12} & \multirow{3}{*}{ 2.3. Stability variation } & Stable & Stable \\
\hline & & & & & & \\
\hline & & & & & Stable & Stable \\
\hline $\begin{array}{l}\text { 3.3. Range of Varia- } \\
\text { tions }\end{array}$ & $28-28$ & $10-26$ & $12-12$ & 3. Level change & & \\
\hline \multirow{2}{*}{$\begin{array}{l}\text { 3.4. Variation range in } \\
\text { stability envelope } \\
25 \% \text { of median }\end{array}$} & \multirow{2}{*}{$\begin{array}{l}21-35 \\
\text { Stable }\end{array}$} & \multirow{2}{*}{$\begin{array}{c}11-25 \\
\text { Variable }\end{array}$} & \multirow{2}{*}{$\begin{array}{l}5-19 \\
\text { Stable }\end{array}$} & \multirow{2}{*}{ 3.1. Relative variation } & 25 & 12 \\
\hline & & & & & 28 & 11 \\
\hline \multirow{3}{*}{ 4. Level change } & \multirow{3}{*}{7} & \multirow{3}{*}{7} & \multirow{3}{*}{7} & \multirow{3}{*}{ 3.2. Absolute variation } & 26 & 12 \\
\hline & & & & & & \\
\hline & & & & & 28 & 10 \\
\hline \multirow{3}{*}{ 4.1. Relative variation } & \multirow{3}{*}{$28-28$} & \multirow{3}{*}{$25-11$} & \multirow{3}{*}{$12-12$} & \multirow{3}{*}{ 3.3. Median variation } & 18 & 12 \\
\hline & & & & & & \\
\hline & & & & & 28 & 18 \\
\hline \multirow{3}{*}{ 4.2. Absolute variation } & \multirow{3}{*}{$28-28$} & \multirow{3}{*}{$26-10$} & & & 18 & 12 \\
\hline & & & $12-12$ & 3.4. mean variation & & \\
\hline & & & & & 28 & 18 \\
\hline 5. Trend & & & & 4. Data overlap & & \\
\hline 5.1. Direction & Zero slope & Decreasing & Zero slope & 4.1. PND & $100 \%$ & $0 \%$ \\
\hline 5.2. Stability & Stable & Stable & Stable & 4.2. POD & $0 \%$ & $100 \%$ \\
\hline 5.3. Multiple routes & No & No & No & & & \\
\hline
\end{tabular}

PND: percentage of non-overlapping data; POD: percentage of overlapping data.

Iranian Rehabilitation Journa

incontinence, constipation, or even more severe health complications, and a poor and inefficient diet might exacerbate the situation. However, the impact of diet change on handling symptoms of neurogenic bowel in patients with SCI is not well understood [20], and the research on the impact of dietary programs/modification on neurogenic bowel symptoms is not enough [21]. In line with the diet modification included in the training program of the present study, a study reported that a diet high in fiber increased the transit time of the colon in patients with SCI and continued constipation [22]. Badiali et al. [15] reported that colon transit time was reduced in patients with SCI after four weeks of a diet with a low residue and scheduled fluid intake.

Similarly, a cross-sectional study [23] indicated that higher fiber intake was strongly correlated with decreased bowel dysfunction. Nevertheless, a different cross-sectional study [24] showed that fiber consumption had no significant effect on bowel complications or bowel-related quality of life. The positive effect of including diet modification in the training program employed for the present study lends further support for the studies [23] that reported the beneficial effect of diet 
Table 4. In-Situation and between-situations analyses for bowel dysfunction management of the third patient

\begin{tabular}{|c|c|c|c|c|c|c|}
\hline In-Situation & & & & Between-Situations & & \multirow{2}{*}{ C } \\
\hline \multirow{3}{*}{ 1. Situations' sequence } & \multirow{3}{*}{ A } & \multirow{3}{*}{ B } & \multirow{3}{*}{ C } & \multirow[t]{2}{*}{ 1. Situation } & \multirow[t]{2}{*}{$\mathrm{B}$} & \\
\hline & & & & & & \\
\hline & & & & comparison & $A$ & B \\
\hline 2. Situations' length & 3 & 4 & 3 & 2. Trend variations & & \\
\hline \multirow{2}{*}{ 3. Level } & & & & \multirow{2}{*}{ 2.1. Direction change } & & \\
\hline & & & & & Zero slope & Decreasing \\
\hline 3.1. Median & 22 & 9 & 3 & 2.2. Target based effect & Positive & Negative \\
\hline \multirow{3}{*}{ 3.2. Mean } & \multirow{3}{*}{22} & \multirow{3}{*}{10.5} & \multirow{3}{*}{3.5} & \multirow{3}{*}{ 2.3. Stability variation } & Stable & Stable \\
\hline & & & & & & \\
\hline & & & & & Stable & Stable \\
\hline 3.3. Range of variations & $22-22$ & $2-22$ & $1-3$ & 3. Level change & & \\
\hline \multirow{2}{*}{$\begin{array}{l}3.4 \text { variation range in } \\
\text { stability envelope } \\
25 \% \text { of median }\end{array}$} & \multirow{2}{*}{$\begin{array}{c}16.5-27.5 \\
\text { Stable }\end{array}$} & \multirow{2}{*}{$\begin{array}{l}3.5-14.5 \\
\text { Variable }\end{array}$} & \multirow{2}{*}{$\begin{array}{l}-2.5-8.5 \\
\text { Stable }\end{array}$} & \multirow{2}{*}{ 3.1. Relative variation } & 15.5 & 2 \\
\hline & & & & & 22 & 5.5 \\
\hline \multirow{3}{*}{ 4. Level change } & \multirow{3}{*}{5.5} & \multirow{3}{*}{5.5} & \multirow{3}{*}{5.5} & \multirow{3}{*}{ 3.2. Absolute variation } & 22 & 3 \\
\hline & & & & & & \\
\hline & & & & & 22 & 2 \\
\hline \multirow{3}{*}{ 4.1. Relative variation } & \multirow{3}{*}{$22-22$} & \multirow{3}{*}{$15.5-5.5$} & \multirow{3}{*}{$2-2$} & \multirow{3}{*}{ 3.3. Median variation } & 9 & 3 \\
\hline & & & & & & \\
\hline & & & & & 22 & 9 \\
\hline \multirow{3}{*}{ 4.2. Absolute variation } & \multirow{3}{*}{$22-22$} & \multirow{3}{*}{$22-2$} & & & 10.5 & 3.5 \\
\hline & & & $3-3$ & 3.4. Mean variation & & \\
\hline & & & & & 22 & 10.5 \\
\hline 5. trend & & & & 4. Data overlap & & \\
\hline 5.1. Direction & Zero slope & Decreasing & Zero slope & 4.1. PND & $75 \%$ & $33.33 \%$ \\
\hline 5.2. Stability & Stable & Stable & Stable & 4.2. POD & $25 \%$ & $66.66 \%$ \\
\hline 5.3. Multiple routes & No & No & No & & & \\
\hline
\end{tabular}

modification (especially modifying the amount of fiber intake) to reduce bowel dysfunction problems.

Abdominal massage is usually recommended in bowel care programs since this massage results in less transit time in the colon [25]. The increased pressure of the abdomen is among the mechanisms that clarify how abdominal massage impacts NBD [26]. Furthermore, peristalsis enhancement is also a mechanism by which abdominal massage influences NBD [26].

In line with the positive effect of massaging the abdomen on bowel dysfunction of patients with SCI, Ayas et al. [25] and Badiali et al. [15] reported the positive effects of massaging the abdomen on some bowel dysfunction aspects. Liu et al. [27] showed that massaging the abdomen produced rectal moves/waves, which, in turn, caused a patient with myelopathy to experience defecation. They surmise that somatoautonomic reflexes might perhaps trigger the rectal waves through massaging the abdomen. Since no study was conducted on the effect of using abdominal massage for patients aging with SCI, the beneficial effect of the present study's training program, which included abdominal massage, might further support the findings of the studies mentioned earlier. 


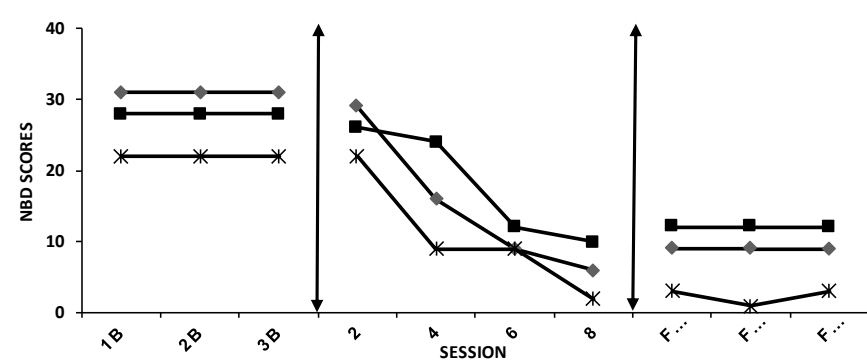

Figure 1. Neurogenic bowel dysfunction scores progression for three patients

Iranian Rehabilitation Journa

B: Baseline; F: follow-up.

Digitation was another technique included in the training program of the present study. Thiruppathy et al. [28] believed that anal digitation could be effectively used in severe bowel dysfunctions such as SCI with satisfactory results. Similar to the present study, perianal and anorectal digitation were included in the treatment protocols for patients with SCI developed by Badiali et al. [15] and Coggrave et al. [16], both of which positively influenced bowel dysfunctions in these patients. In general, the combination of the techniques used in the training program used in this study was helpful for patients aged SCI with bowel dysfunction.

Last but not least, since more people with SCI live longer due to medical advancement, the issues regarding aging with SCI present new challenges for patients with SCI, their caregivers, and providers of healthcare services to facilitate successful aging. The ability to face these challenges and lack of independence primarily impact the quality of life in those with SCI. One of these challenges is bowel dysfunction problems, which increase by age.

With regard to the strength of the study, this research is among the first studies focusing on bowel dysfunction and care in men aging with SCI and aimed to increase the awareness of the public healthcare system of the needs of the individuals with SCI who are getting old with this debilitating disease.

\section{Study limitations}

As no training program was found for the patients aged with SCI, the present researchers devised one based on $[15,16]$. However, some limitations need to be taken into account in the present study and the interpretation of the findings. The most important limitation was the small sample size. As a result of the single-case design adopted for the present study, only three participants were recruited. Furthermore, the participants were limited to the men since only male patients with SCI were admitted to the rehabilitation center in which the present study was conducted. Another limitation was that the data collection was done by a self-report measure (i.e.,
NBD). Although NBD is one of the most reliable and frequently used measures of how severe colorectal dysfunction in individuals with SCI is [29], the findings are limited to the factors and aspects included in it. Finally, since no Persian training videos existed, the researchers were forced to use the English ones.

\section{Study implications}

Prolonged time for bowel care completion in patients with SCI is among the most distressing and frustrating aspects of care for them and their caregivers. Therefore, healthcare professionals need to help patients find ways to make this process less burdensome. For example, they might ask the patients to drink more liquid, hot liquid, because increased fluid intake helps prevent hard stool caused by the decreased colonic transit time.

Another factor related to the diet that needs to be controlled by healthcare professionals is fiber intake. Highfiber diets should not be uniformly included in the bowel care program. Instead, healthcare professionals should take the patients' diet history to reveal their routine intake of fiber and evaluate the way it influences the consistency of stool and frequency of evacuation.

Emphasizing the healthcare professionals' role in planning the required programs does not mean excluding the patients. The patients should also be encouraged to choose the method and timing, and supplies to complete their bowel care. Besides, healthcare professionals should continuously evaluate the quality of the current bowel management methods or whether further interventions need to be considered.

\section{Conclusion}

The study findings revealed the efficacy of the training program for the patients aged with SCI. The findings further confirm the need for developing bowel manage- 
ment training programs for the under-addressed issue of complications resulting from aging with SCI.

\section{Ethical Considerations}

\section{Compliance with ethical guidelines}

The experimental procedures were approved by the Ethics Committee for research involving human participants at Islamic Azad University, Najafabad Branch (Code: IR.ISAAR.REC.1398.007). The procedures observed the ethical standards of the Helsinki Declaration of 1975 , as revised in 1983.

\section{Funding}

This research did not receive any grant from funding agencies in the public, commercial, or non-profit sectors.

\section{Authors' contributions}

Conceptualization, investigation, and writing - original draft: Mohammadreza Abed and Zohreh Raeisi; Methodology, supervision, writing - review, and editing: Hasan Rezaei-Jamalouei and Mohammadreza Abed; Resources and analysis: Mojtaba Ansari Shahidi.

\section{Conflict of interest}

The authors declared no conflict of interest.

\section{References}

[1] Glickman S, Kamm MA. Bowel dysfunction in spinalcord-injury patients. The Lancet. 1996; 347(9016):1651-3. [DOI:10.1016/S0140-6736(96)91487-7][PMID]

[2] Hou S, Rabchevsky AG. Autonomic consequences of spinal cord injury. Comprehensive Physiology. 2011; 4(4):1419-53. [DOI:10.1002/cphy.c130045] [PMID]

[3] Burns AS, St-Germain D, Connolly M, Delparte JJ, Guindon A, Hitzig SL, et al. Phenomenological study of neurogenic bowel from the perspective of individuals living with spinal cord injury. Archives of Physical Medicine and Rehabilitation. 2015; 96(1):49-55. [DOI:10.1016/j.apmr.2014.07.417] [PMID]

[4] Levi R, Hultling C, Nash MS, Seiger A. The Stockholm spinal cord injury study: 1 . Medical problems in a regional SCI population. Paraplegia. 1995; 33(6):308-15. [DOI:10.1038/ sc.1995.70] [PMID]

[5] Krogh K, Nielsen J, Djurhuus JC, Mosdal C, Sabroe S, Laurberg S. Colorectal function in patients with spinal cord lesions. Diseases of the Colon and Rectum. 1997; 40(10):1233-9. [DOI:10.1007/BF02055170] [PMID]
[6] Lynch AC, Wong C, Anthony A, Dobbs BR, Frizelle FA Bowel dysfunction following spinal cord injury: A description of bowel function in a spinal cord-injured population and comparison with age and gender matched controls. Spinal Cord. 2000; 38(12):717-23. [DOI:10.1038/sj.sc.3101058] [PMID]

[7] Charlifue SW. A collaborative longitudinal study of aging with spinal cord injury: Overview of the background and methodology. Topics in Spinal Cord Injury Rehabilitation. 2007; 12(3):1-14. [DOI:10.1310/sci1203-1]

[8] Menter R, Weitzenkamp D, Cooper D, Bingley J, Charlifue $\mathrm{S}$, Whiteneck G. Bowel management outcomes in individuals with long-term spinal cord injuries. Spinal Cord. 1997; 35(9):608-12. [DOI:10.1038/sj.sc.3100461] [PMID]

[9] Liem NR, McColl MA, King W, Smith KM. Aging with a spinal cord injury: Factors associated with the need for more help with activities of daily living. Archives of Physical Medicine and Rehabilitation. 2004; 85(10):1567-77. [DOI:10.1016/j. apmr.2003.12.038] [PMID]

[10] Charlifue S, Jha A, Lammertse D. Aging with spinal cord injury. Physical Medicine and Rehabilitation Clinics of North America. 2010; 21(2):383-402. [DOI:10.1016/j.pmr.2009.12.002] [PMID]

[11] Whiteneck GG, Charlifue SW, Frankel HL, Fraser MH, Gardner BP, Gerhart KA, et al. Mortality, morbidity, and psychosocial outcomes of persons spinal cord injured more than 20 years ago. Paraplegia. 1992; 30(9):617-30. [DOI:10.1038/ sc.1992.124] [PMID]

[12] Valles M, Vidal J, Clav P, Mearin F. Bowel dysfunction in patients with motor complete spinal cord injury: Clinical, neurological, and pathophysiological associations. The American Journal of Gastroenterology. 2006; 101(10):2290-9. [DOI:10.1111/j.1572-0241.2006.00729.x] [PMID]

[13] Krasny-Pacini A, Evans J. Single-case experimental designs to assess intervention effectiveness in rehabilitation: A practical guide. Annals of Physical and Rehabilitation Medicine. 2018; 61(3):164-79. [DOI:10.1016/j.rehab.2017.12.002] [PMID]

[14] Krogh K, Christensen P, Sabroe S, Laurberg S. Neurogenic bowel dysfunction score. Spinal Cord. 2006; 44(10):625-31. [DOI:10.1038/sj.sc.3101887] [PMID]

[15] Badiali D, Bracci F, Castellano V, Corazziari E, Fuoco U, Habib FI, et al. Sequential treatment of chronic constipation in paraplegic subjects. Spinal Cord. 1997; 35(2):116-20. [DOI:10.1038/sj.sc.3100355] [PMID]

[16] Coggrave MJ, Norton C. The need for manual evacuation and oral laxatives in the management of neurogenic bowel dysfunction after spinal cord injury: A randomized controlled trial of a stepwise protocol. Spinal Cord. 2010; 48(6):504-10 [DOI:10.1038/sc.2009.166] [PMID]

[17] Fisher WW, Kelley ME, Lomas JE. Visual aids and structured criteria for improving visual inspection and interpretation of single-case designs. Journal of Applied Behavior Analysis. 2003; 36(3):387-406. [DOI:10.1901/jaba.2003.36-387] [PMID] [PMCID]

[18] Morgan DL, Morgan RK. Single-case research methods for the behavioral and health sciences. New York: SAGE Publications; 2008. [DOI:10.4135/9781483329697]

[19] Krassioukov A, Eng JJ, Claxton G, Sakakibara BM, Shum S. Neurogenic bowel management after spinal cord injury: 
A systematic review of the evidence. Spinal Cord. 2010; 48(10):718-33. [DOI:10.1038/sc.2010.14] [PMID] [PMCID]

[20] Stoffel JT, Van der Aa F, Wittmann D, Yande S, Elliott S Neurogenic bowel management for the adult spinal cord injury patient. World Journal of Urology. 2018; 36(10):1587-92. [DOI:10.1007/s00345-018-2388-2] [PMID]

[21] Yeung HY, Iyer P, Pryor J, Nicholson M. Dietary management of neurogenic bowel in adults with spinal cord injury: An integrative review of literature. Disability and Rehabilitation. 2021 43(9):1208-19. [DOI:10.1080/09638288.2019.1652702] [PMID]

[22] Cameron KJ, Nyulasi IB, Collier GR, Brown DJ. Assessment of the effect of increased dietary fiber intake on bowel function in patients with spinal cord injury. Spinal Cord. 1996; 34(5):277-83. [DOI:10.1038/sc.1996.50] [PMID]

[23] Tate DG, Forchheimer M, Rodriguez G, Chiodo A, Cameron AP, Meade $\mathrm{M}$, et al. Risk factors associated with neurogenic bowel complications and dysfunction in spinal cord injury. Archives of Physical Medicine and Rehabilitation. 2016; 97(10):1679-86. [DOI:10.1016/j.apmr.2016.03.019] [PMID]

[24] Forchheimer M, Meade MA, Tate D, Cameron AP, Rodriguez $\mathrm{G}$, DiPonio L. Self-report of behaviors to manage neurogenic bowel and bladder by individuals with chronic spinal cord injury: Frequency and associated outcomes. Topics in Spinal Cord Injury Rehabilitation. 2016; 22(2):85-98. [DOI:10.1310/sci2202-85] [PMID] [PMCID]

[25] Ayas S, Leblebici B, Sözay S, Bayramoglu M, Niron EA. The effect of abdominal massage on bowel function in patients with spinal cord injury. American Journal of Physical Medicine \& Rehabilitation. 2006; 85(12):951-5. [DOI:10.1097/01. phm.0000247649.00219.c0] [PMID]

[26] Stiens SA, Bergman SB, Goetz LL. Neurogenic bowel dysfunctions after spinal cord injury: Clinical evaluation and rehabilitative management. Archives of Physical Medicine and Rehabilitation. 1997; 78(3 Suppl):S86-102. [DOI:10.1016/ S0003-9993(97)90416-0][PMID]

[27] Liu Z, Sakakibara R, Odaka T, Uchiyama T, Yamamoto $\mathrm{T}$, Ito $\mathrm{T}$, et al. Mechanism of abdominal massage for difficult defecation in a patient with myelopathy (HAM/TSP). Journal of Neurology. 2005; 252(10):1280-2. [DOI:10.1007/s00415-0050825-9] [PMID]

[28] Thiruppathy K, Preziosi G, Bajwa A, Sharma P, Cerdeira M. Multiple sclerosis related bowel dysfunction: Pathophysiology, clinical manifestation and management. Journal of Neurology \& Neurophysiology. 2014; 5(255):2-5. [DOI:10.4172/2155-9562.1000255]

[29] Johns J, Krogh K, Rodriguez GM, Eng J, Haller E, Heinen M, et al. Management of neurogenic bowel dysfunction in adults after spinal cord injury: Clinical practice guideline for health care providers. The Journal of Spinal Cord Medicine. 2021; 44(3):442-510. [DOI:10.1080/10790268.2021.1883385] [PMID] 
This Page Intentionally Left Blank 